\title{
Functionalization of Polypropylene with High Dielectric Properties: Applications in Electric Energy Storage
}

\author{
T. C. Mike Chung \\ Department of Materials Science and Engineering, The Pennsylvania State University, University Park, USA \\ Email: chung@ems.psu.edu
}

Received March 15, 2012; revised April 13, 2012; accepted April 25, 2012

\begin{abstract}
Biaxial-oriented polypropylene (BOPP) thin films are currently used as dielectrics in state-of-the-art capacitors that show many advantages, such as low energy loss and high breakdown strength, but a limited energy density $\left(<2 \mathrm{~J} / \mathrm{cm}^{3}\right)$. This paper reviews some of our experimental results in functionalization of polypropylene with the objective to increase its electric energy density and maintain all desirable properties. A family of PP copolymers with various moieties, such as $\mathrm{OH}, \mathrm{O}-\mathrm{Si}\left(\mathrm{CH}_{3}\right)_{3}$, long chain branching, and cross-linking structure, have been systematically synthesized and studied to examine their dielectric properties (i.e. dielectric constant, dielectric loss, breakdown strength, polarization under various temperatures and electric fields). Evidently, a high molecular weight poly(propylene-co-hexen-6-ol) copolymer (PP-OH) containing $4.2 \mathrm{~mol} \%$ of polar $\mathrm{OH}$ groups shows a dielectric constant $(\varepsilon)$ of about 4.6 (more than 2 times of BOPP) - which is independent on a wide range of temperatures and frequencies - and high breakdown strength $>600$ $\mathrm{MV} / \mathrm{m}$. The PP-OH dielectric demonstrates a linear reversible charge storage behavior with high releasing energy density $>7 \mathrm{~J} / \mathrm{cm}^{3}$ (2 - 3 times of BOPP) after an applied electric field at $\mathrm{E}=600 \mathrm{MV} / \mathrm{m}$, without showing any significant increase of energy loss and remnant polarization at zero electric field. On the other hand, a cross-linked polypropylene (x-PP) exhibits an $\varepsilon \sim 3$, which is independent of a wide range of temperatures and frequencies, slim polarization loops, high breakdown strength $(\mathrm{E}=650 \mathrm{MV} / \mathrm{m})$, narrow breakdown distribution, and reliable energy storage capacity $>5$ $\mathrm{J} / \mathrm{cm}^{3}$ (double that of state-of-the-art BOPP capacitors), without showing any increase in energy loss.
\end{abstract}

Keywords: Capacitor; Dielectric; Energy Storage; Polypropylene; Functional Polyolefin

\section{Introduction}

Energy storage has long been a scientifically challenging and industrially important area [1]. and is an essential element to energy utilization and management. An effective electric storage technology that might exist today could eliminate most of our concerns on more nuclear or coal-fired electric generators, enable emulsion-free electric automobiles, and expand the usage of clean energy sources (solar, wind, hydroelectric, etc.) around the clock, as well as effectively address associated environmental and economic problems.

Capacitors [2,3] are passive electronic components that store energy in the form of an electrostatic field. In their simplest form, capacitors consist of two conducting plates (positive and negative electrodes) separated by an insulating material called the dielectric - which can be air, ceramics, polymers, etc. Opposite to batteries, which have high energy density and low power density, capacitors usually exhibit high power density but low energy density, as illustrated in Figure 1. The scientific challenge is to increase the energy density of the capacitor,

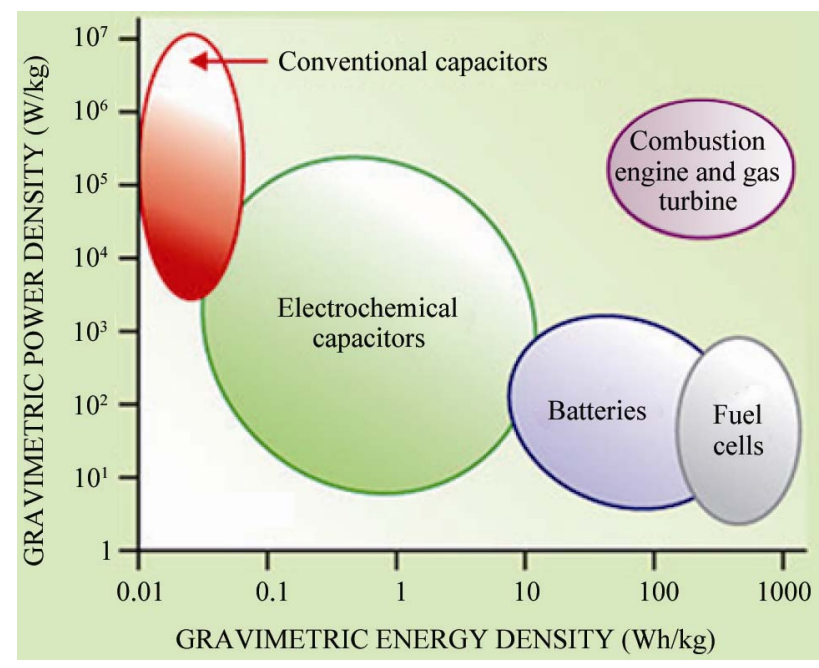

Figure 1. Energy and power density of energy storage devices.

which is governed by the dielectric material. Ceramic capacitors $[4,5]$ made from layers of ceramic dielectric material, such as lead zirconate titanate, have been ex- 
ploited to fabricate high energy density capacitors. However, there are disadvantages with the matter of a relatively low breakdown voltage and unrecoverable breakdown in the capacitor structure. They must be designed conservatively with significantly reduced energy density in the device level.

On the other hand, the metallized polymer film capacitors [6,7] have attracted a great deal of attention due to their desirable properties, such as light weight, low cost, and excellent processibility for forming thin film with a large surface area. They also demonstrate flexibility and toughness under stress, and the ability to be packaged into a desirable configuration. Some polymer capacitors - based on semi-crystalline thermoplastics, such as polyester, polycarbonate, polypropylene - show self-healing [8] after a puncture, which merely results in a gradual loss of capacitance so that they can be operated near the breakdown voltage. The advanced metallized polymer film capacitors, using biaxial oriented polypropylene (BOPP) thin film $[9,10]$, show noticeably high dielectric strength (breakdown electric field $>600 \mathrm{MV} / \mathrm{m}$ ) and the self-healing phenomenon. Despite the low dielectric constant $(\varepsilon=2.2)$, BOPP thin film produces decent and reliable releasing energy density in the range of $1-2 \mathrm{~J} / \mathrm{cc}$ $(0.3-0.6 \mathrm{Wh} / \mathrm{Kg})$ and exhibits almost no energy loss during the charging-discharging cycles. Many BOPP based capacitors, offering high power densities and significant energy storage capacities, are currently used as pulse power conditions in commercial and military devices.

$$
\text { Energy density }(\mathrm{J} / \mathrm{cc})=\frac{1}{2} \varepsilon \varepsilon_{\mathrm{o}} \mathrm{E}^{2}=\frac{1}{2} \varepsilon \varepsilon_{\mathrm{o}}(\mathrm{V} / \mathrm{d})^{2}
$$

$\left(\varepsilon_{0}\right.$ : permittivity of free space $\left.=8.85 \times 10^{-12} \mathrm{~F} / \mathrm{m}\right)$.

Equation (1) shows the energy density equation and Table 1 illustrates several hypothetical situations in the ideal capacitors, a defect-free polymer thin film with a dielectric constant $\varepsilon=2.2$ in PP, thickness $(\mathrm{d}=10 \mu \mathrm{m})$, and an applied voltage $\mathrm{V}=5 \mathrm{kV}(\mathrm{E}=500 \mathrm{MV} / \mathrm{m})$ can offer a maximum energy density of $2.4 \mathrm{~J} / \mathrm{cc}(0.74 \mathrm{Wh} / \mathrm{Kg})$ at material level, similar to that of experimental result. A further increase of the electric field to $E=1000 \mathrm{MV} / \mathrm{m}$ can result in a theoretical energy density of $9.6 \mathrm{~J} / \mathrm{cc}(0.74$

Table 1. Theoretical estimate of energy density under several hypothetic conditions.

\begin{tabular}{cccc}
\hline \multirow{2}{*}{ Dielectric constant $(\varepsilon)$} & Applied Field $(\mathrm{MV} / \mathrm{m})$ & \multicolumn{2}{c}{ Energy Density } \\
\cline { 3 - 4 } & & $(\mathrm{J} / \mathrm{cc})$ & $\mathrm{Wh} / \mathrm{kg}^{*}$ \\
\hline 2.2 & 500 & 2.4 & 0.74 \\
2.2 & 1000 & 9.6 & 2.98 \\
50 & 500 & 54 & 16.8 \\
50 & 1000 & 216 & 67.2 \\
\hline
\end{tabular}

*Polymer density: $0.9 \mathrm{~g} / \mathrm{cc}$.
$\mathrm{Wh} / \mathrm{Kg}$ ). On the other hand, the increase of the polymer dielectric constant to $\varepsilon=50$ (in the range of some fluoroterpolymers) with $\mathrm{E}=500$ and $1000 \mathrm{MV} / \mathrm{m}$ can result in a theoretical energy density of 54 and $216 \mathrm{~J} / \mathrm{cc}$, respectively, which are significantly higher than the experimental values due to undesirable energy loss (discussed later). It would be theoretically possible to increase to more than a 50 folds energy density to $100 \mathrm{~J} / \mathrm{cc}$ (30 $\mathrm{Wh} / \mathrm{Kg}$ ) in the battery range if we could develop an advance dielectric material that shows several essential characteristics. These characteristics require that: 1) the polymer should exhibit a high dielectric constant $(\varepsilon>50)$ at the operation temperature, 2) the polymer can be processed into defect-free and uniform thin films $(d=10$ $\mu \mathrm{m})$ with good mechanical strength and a high breakdown voltage $(\mathrm{E}>1000 \mathrm{MV} / \mathrm{m})$, and 3) the polymer should have a desirable polar crystalline structure (generally, high crystallinity and small crystal size) that exhibits reversible polarization-depolarization behavior with low loss $(\tan \delta<0.01)$.

Figure 2 shows a hypothetical D-E loop (charge displacement vs. applied electric field). During the charging (polarization) cycle, the total energy density $\left(\mathrm{U}_{\text {charge }}\right)$ charged to the capacitor is estimated by integrating the area $U_{\text {charge }}=\int E d D_{\text {charge }}$ (E: applied electric field; $D_{\text {charge }}$ : charge displacement in the charging cycle). However, the energy density $\left(\mathrm{U}_{\text {discharge }}\right)$ of the capacitor shall be the total energy released during the discharging cycle, by integrating the area $U_{\text {discharge }}=\int \mathrm{E} d \mathrm{D}_{\text {discharge }}\left(\mathrm{D}_{\text {discharge }}\right.$ : charge displacement in the discharging cycle). The difference, $\mathrm{U}_{1}=\mathrm{U}_{\text {charge }}-\mathrm{D}_{\text {discharge}}$, is the energy loss $\left(\mathrm{U}_{1}\right)$, which is equal to the area enclosed by the charging and discharging cycle. Ideally, the polymer chains are polarized by an applied electric field during the polarization (charging) cycle to a high field (before breakdown), and

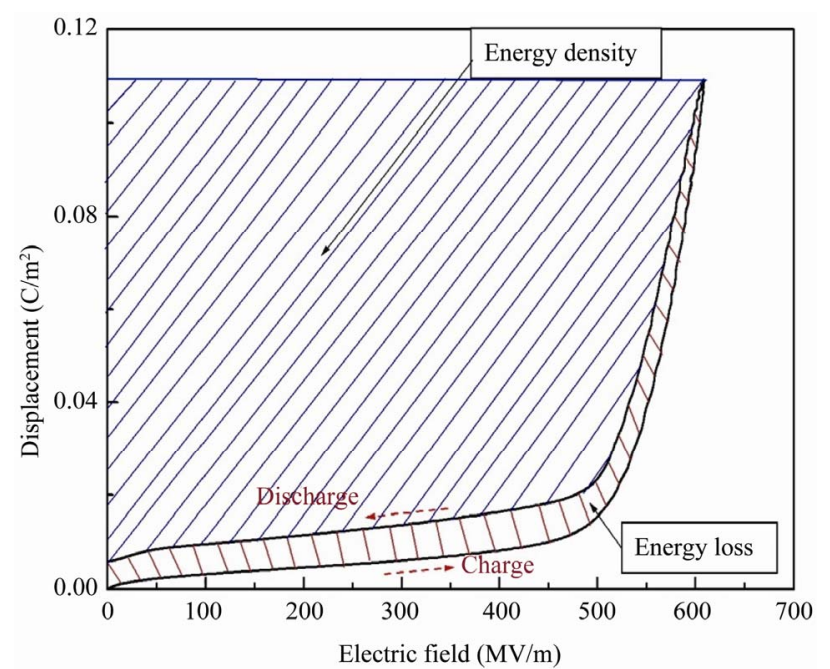

Figure 2. A D-E loop showing energy density and energy loss. 
are completely reversible (with very low hysteresis in the loop), without remnant polarization at $\mathrm{E}=0$, and coercive electric field at $\mathrm{D}=0$.

\section{Results and Discussion}

In the past decade, we have been studying two polymer systems, including long chain branched polypropylene (LCBPP) [11,12] and VDF fluoropolymers [13-15], for polymer film capacitors. Two systems represent two different approaches to increase energy density, either by increasing the breakdown field (E) in PP case or increasing the dielectric constant $(\varepsilon)$ in PVDF case. PP with linear molecular structure exhibits low melt strength and presents challenge in forming defect-free uniform thin films (thickness $<10 \mu \mathrm{m}$ ). LCBPP structure dramatically increases melt strength and allows the melt process to form high quality thin films. With the combination of high melt strength and a bi-axially stretching technique, some LCBPP thin films (thickness $<10 \mu \mathrm{m}$ ) were prepared, and they exhibited significant increase in mechanical properties. On the other hand, some PVDF terpolymers, exhibiting high dielectric constants $\varepsilon>60$ and relaxed ferroelectric properties, can offer large charge displacements via polar crystals. Figure 3 compares two D-E loops of a LCBPP polymer and a ferroelectric PVDF fluoro-terpolymer (ferroelectric relaxor) with the composition VDF/TrFE/CTFE $=65.6 / 26.7 / 7.7 \mathrm{~mol} \%$, which were prepared by borane-mediated control radical polymerization. The terpolymers show narrow molecular weight and composition distributions [16].

In LCBPP case, the thin D-E loop indicates reversible linear polarization-depolarization profile (similar to that of BOPP), with almost no energy loss. Some high quality thin films (thickness $<10 \mu \mathrm{m}$ ) show very high breakdown electric fields $>1000 \mathrm{MV} / \mathrm{m}$ (vs. $<700 \mathrm{MV} / \mathrm{m}$ in BOPP case), which can deliver a high energy density $\sim 10$ $\mathrm{J} / \mathrm{cc}$ at $\mathrm{E}=1000 \mathrm{MV} / \mathrm{m}$ - four times higher than that of state-of-the-art PP capacitors. This experimental energy density is also consistent with that of the predicted value in Table 1. On the other hand, the VDF/TrFE/CTFE fluoro-terpolymer (65.6/26.7/7.7 mol\%), has a high $\varepsilon \sim 60$, exhibits a large charge displacement $\sim 0.1 \mathrm{C} / \mathrm{m}^{2}$, but early polarization in the low field range and dielectric saturation in the high field range; this is accompanied by some hysteresis during the depolarization cycle [16,17]. The maximum charging energy density is $\sim 25 \mathrm{~J} / \mathrm{cc}$ at $\mathrm{E}=$ $500 \mathrm{MV} / \mathrm{m}$, and the energy loss is $\sim 30 \%$. The significantly lower charging energy density, less than half of the predicted value under this electric field (Table 1), is largely due to the undesirable polarization-depolarization profile showing early dielectric saturation. Overall, the VDF-based fluoropolymers have shown high energy density, however the coercivity inherent to a ferroelectric still results in very high loss. The energy loss, which generates large amount of heat during the discharging cycle, is a major concern in thin film capacitors, especially for the pulsed power applications.

In recent years, we have been focusing on functional polypropylene (f-PP) structures, including hydroxylated PP (PP-OH) [18-20] and cross-linked PP (x-PP) [21,22], with the general research objective to simultaneously increase dielectric activities without compromising dielectric loss and breakdown strength. Based on the desirable linear and reversible polarization-depolarization profile (slim D-E loops) for PP structure, we have adopted a strategy to decorate the polymer chain with some selected moieties (via comonomer units) that not only increase dielectric constant but also exhibit reversible polarization. In synthesis, the goal is to prepare the f-PP copolymers with high molecular weight, high crystallinity, and uniform copolymer structures. Equation (2), illustrates two reaction steps to prepare PP-OH copolymer (I). First, the transition metal-mediated propylene copolymerization with few percentages of borane-containing $\alpha$ olefin comonomers was applied to prepare high molecular weight copolymers. Subsequently, the borane copolymer was completely interconverted to the objective PP-OH copolymer (I) under mild oxidative condition (see the equation below).

Table 2 summarizes the experimental results of PP-

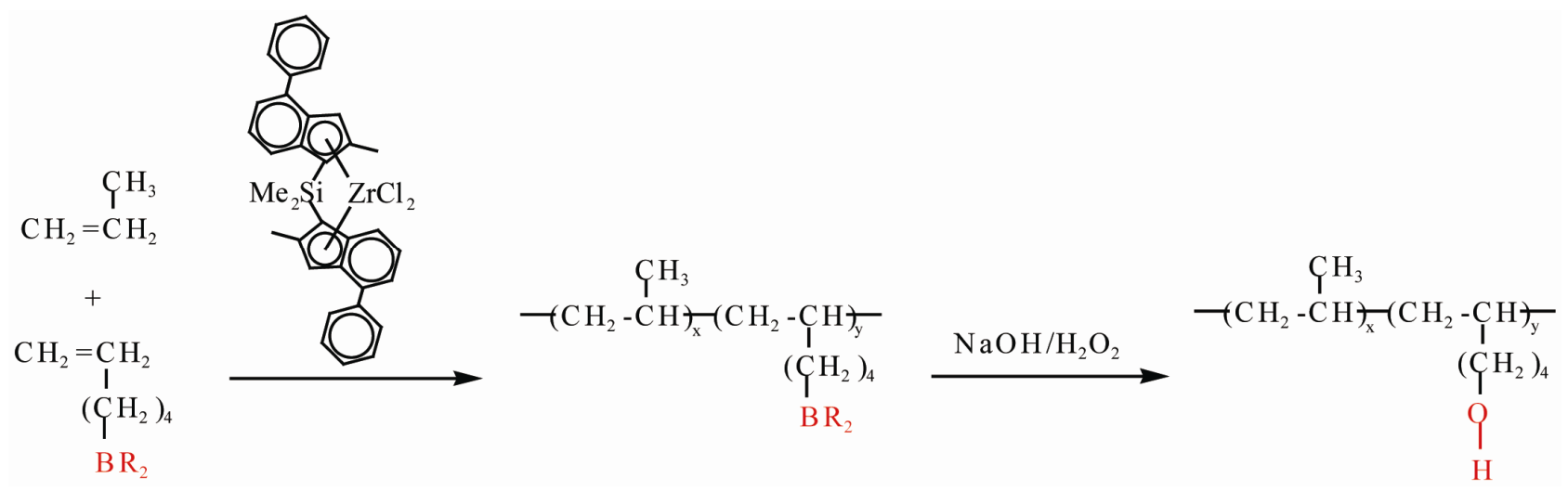




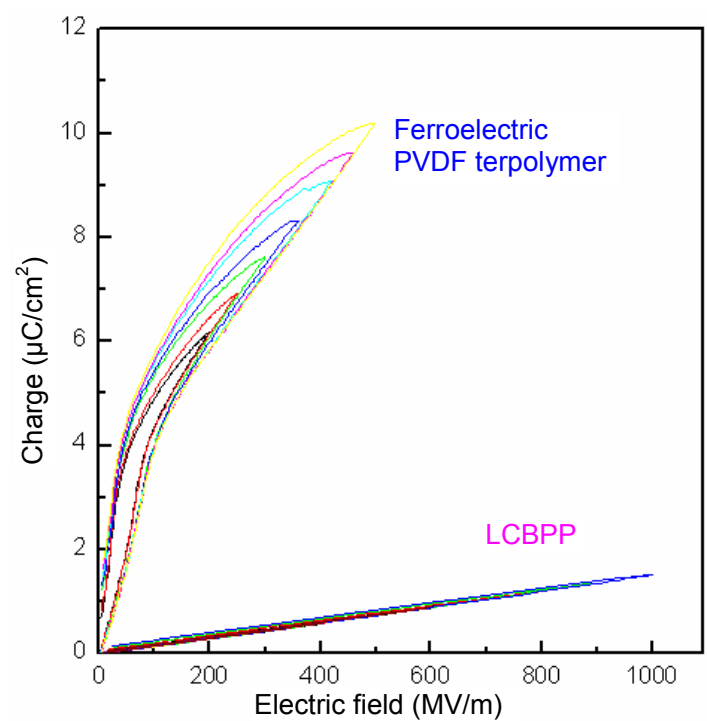

Figure 3. D-E loops for LCBPP and fluoropolymer (VDF/ TrFE $/$ CTFE $=65.6 / 26.7 / 7.7 \mathrm{~mol} \%$ ).

$\mathrm{OH}$ copolymers prepared by the heterogeneous $\mathrm{TiCl}_{3} \mathrm{AA} /$ $\mathrm{Et}_{2} \mathrm{AlCl}$ catalyst. Despite the unfavorable incorporation of large comonomers, we were able to find the reaction condition to prepare $\mathrm{PP}-\mathrm{OH}$ containing $>4 \mathrm{~mol} \% \mathrm{OH}$ comonomer units, which is sufficient for showing the effects of $\mathrm{OH}$ groups in dielectric and capacitor properties. The crystalline morphology of the PP-OH copolymers was examined by DSC measurement, shown in Figure 4. Both $T_{m}$ and $\triangle H_{m}$ values show an initial reduction, then subsequently level off at the higher comonomer incorporation. Both PP-OH-1 and PP-OH-2 show higher crystallization temperature $\left(\mathrm{T}_{\mathrm{c}}\right)$ than the PP homopolymer, indicating that the $\mathrm{OH}$ groups may also facilitate the crystallization process. It is also interesting to note that due to low comonomer reactivity for the borane comonomer in the heterogeneous Ziegler-Natta catalyst, the resulting PP-OH copolymer (I) may have a tapered molecular structure, with the $\mathrm{OH}$-containing side chain units concentrated at one end of the copolymer main chain. Therefore, the increase of comonomer content has less effect on the PP chain crystallization.

Figure 5 shows dielectric constant (top) and dielectric loss (bottom) of several PP-OH copolymers (I) contain- ing 0, 0.7, 1.8 and $4.2 \mathrm{~mol} \% \mathrm{OH}$ comonomer units, as well as the BOPP reference. The dielectric constant increases proportionally with the $\mathrm{OH}$ content. The $\varepsilon$ value of PP-OH-3 with $4.2 \mathrm{~mol} \%$ of the $\mathrm{OH}$ comonomer content reaches about 4.6 (more than 2 times that of BOPP). It is a pleasant surprise for us to observe all $\mathrm{PP}-\mathrm{OH}$ dielectric profiles resembling the PP profile, with a dielectric constant $(\varepsilon)$ that is independent over a wide range of frequencies (between 100 and $1 \mathrm{M} \mathrm{Hz}$ ) and temperatures (between -20 and $100^{\circ} \mathrm{C}$ ). These overlapped and flat dielectric constant lines imply a fast polarization response for the PP-OH (I) copolymer, even under a relatively low electric field condition. On the other hand, all $\mathrm{PP}-\mathrm{OH}$ copolymers also exhibit similar dielectric loss spectra (resemble to that of BOPP); the loss maintains very low ( $\tan \delta$
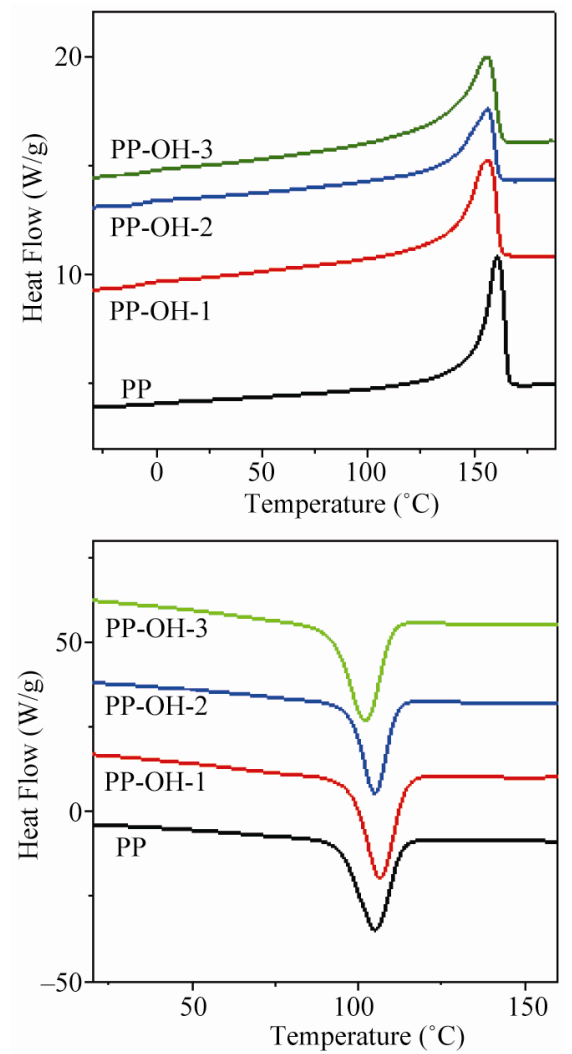

Figure 4. DSC heating (top) and cooling (bottom) curves of PP and three PP-OH copolymers.

Table 2. Summary of poly(propylene-co-hexen-6-ol).

\begin{tabular}{cccccccc}
\hline Runs $^{\mathrm{a}}$ & Polymer & {$[\mathrm{Y}]^{\mathrm{b}}(\mathrm{mol} \%)$} & $\mathrm{M}_{\mathrm{v}}\left(\times 10^{-3} \mathrm{~g} / \mathrm{mol}\right)$ & $\mathrm{T}_{\mathrm{m}}\left({ }^{\circ} \mathrm{C}\right)$ & $\triangle \mathrm{H}_{\mathrm{m}}(\mathrm{J} / \mathrm{g})$ & $\mathrm{T}_{\mathrm{c}}\left({ }^{\circ} \mathrm{C}\right)$ & $\mathrm{T}_{\mathrm{g}}\left({ }^{\circ} \mathrm{C}\right)$ \\
\hline Control & PP & 0 & 961 & 160.9 & 78.0 & 104.9 & - \\
1 & PP-OH-1 & 0.7 & 490 & 156.7 & 66.1 & 106.5 & -3.1 \\
2 & PP-OH-2 & 1.8 & 592 & 156.6 & 65.4 & 104.9 & -2.3 \\
3 & PP-OH-3 & 4.2 & 392 & 156.2 & 65.2 & 102.0 & 0.73 \\
\hline
\end{tabular}

${ }^{\mathrm{a}} \mathrm{Runs}$ : $0.200 \mathrm{~g} \mathrm{TiCl}_{3}$. AA, $5 \mathrm{ml} \mathrm{Al}(\mathrm{Et})_{2} \mathrm{Cl}\left(10 \mathrm{wt} \%\right.$ in toluene), $75 \mathrm{ml}$ toluene, $60^{\circ} \mathrm{C}$, propylene gas pressure: $30 \mathrm{psi}$; ${ }^{b}[\mathrm{Y}]$ indicates the comonomer content $(\mathrm{mol} \%)$ in the copolymers. 
$<0.001)$ in the frequency between 1000 and $1,000,000$ $\mathrm{Hz}$ range and temperature between $-20^{\circ} \mathrm{C}$ and $100^{\circ} \mathrm{C}$.

Figure 6 shows D-E loops (top) and energy density (bottom) of several PP-OH copolymers (I) containing 0 , $0.7,1.8$ and $4.2 \mathrm{~mol} \% \mathrm{OH}$ comonomer units, as well as the BOPP reference. All PP-OH copolymers exhibit similar linear and slim D-E loops (resemble to BOPP); the slope of the D-E loop increases with the $\mathrm{OH}$ content, consistent with the dielectric results. In addition, it maintains constant over a wide range of applied electric fields, up to $\mathrm{E}=600 \mathrm{MV} / \mathrm{m}$. The charge displacement of PP$\mathrm{OH}-3$ reaches $2.4 \mu \mathrm{C} / \mathrm{cm}^{2}$ at $600 \mathrm{MV} / \mathrm{m}$, which is double that of PP under the same applied electric field. Evidently, the dielectric loss maintains very small, with even the PP-OH copolymers exhibiting significantly higher dielectric activities. Figure 6 (bottom) compares the energy density of the same four PP and PP-OH polymers. The energy density $\left(\mathrm{U}_{\mathrm{e}}=\int \mathrm{E} d \mathrm{D}_{\text {discharging }}\right)$ is estimated from the discharging cycle in Figure 6 (top), which clearly increases with the $\mathrm{OH}$ content and exponentially increases with the applied electric field (E). At the applied electric field $\mathrm{E}=600 \mathrm{MV} / \mathrm{m}$, the energy density for PP-OH-3 reaches $7.42 \mathrm{~J} / \mathrm{cm}^{3}$ - more than double that shown in BOPP capacitors. Most importantly, the increase of energy density does not cause an increase in energy loss (the area enclosed by the charging-discharging cycle), which remains very low (similar to PP) for all $\mathrm{PP}-\mathrm{OH}$ copolymers.

The $\mathrm{OH}$ groups in the flexible side chains clearly contribute to the polarizability of the PP-OH (I) with the unexpected large scale, which may be originated from the induced electronic polarization of $\mathrm{OH}$ groups along with the local dipole orientation. It is intriguing to observe (the first time) polar group reversible polarization. As illustrated in Figure 7, the flexible $\mathrm{OH}$ groups may form inter-chain H-bondings with a network structure that provides reversible segment stability even when the temperature rises up to $100^{\circ} \mathrm{C}$. A FTIR spectrum of PP$\mathrm{OH}-3$ also shows a broad $\mathrm{OH}$ absorption band peaked at $3300 \mathrm{~cm}^{-1}$, indicating H-bonding between $\mathrm{OH}$ groups in the PP-OH copolymer.

It is very curious to further understand the $\mathrm{OH}$ group effects in the PP-OH polarization. As shown in Equation 3 , the PP-OH polymer (I) was modified by reacting $\mathrm{OH}$ groups with $\mathrm{Cl}$-silane reagent to block all H-bondings in the resulting PP-O-Si( $\left(\mathrm{CH}_{3}\right)_{3}$ copolymer (II). Furthermore, the $\mathrm{OH}$ groups were reacted with a diisocyanate compound to form a chemical cross-linked network structure (III). Both reactions are very effective to reach the complete conversion of $\mathrm{OH}$ groups (see the equation below).

Figure 8 (top) compares dielectric constant of PP$\mathrm{OSi}\left(\mathrm{CH}_{3}\right)_{3}$ (II) with the corresponding PP-OH (I) containing $4.2 \mathrm{~mol} \% \mathrm{OH}$ group (PP-OH-3) and PP homopolymer. Deviating from PP and PP-OH profiles (independent on frequency and temperature), the $\varepsilon$ value of $\mathrm{PP}-\mathrm{OSi}\left(\mathrm{CH}_{3}\right)_{3}$ proportionally decreases with the increase of frequency and temperature. In Figure 8 (bottom), we also observed the broad hysteresis in the D-E loops of PP-OSi $\left(\mathrm{CH}_{3}\right)_{3}$ (II) copolymer, which increases with the applied electric field. The combination of the dielectric constant (vs. temperature and frequency) and polarization loops (vs. applied electric field) results clearly indicates

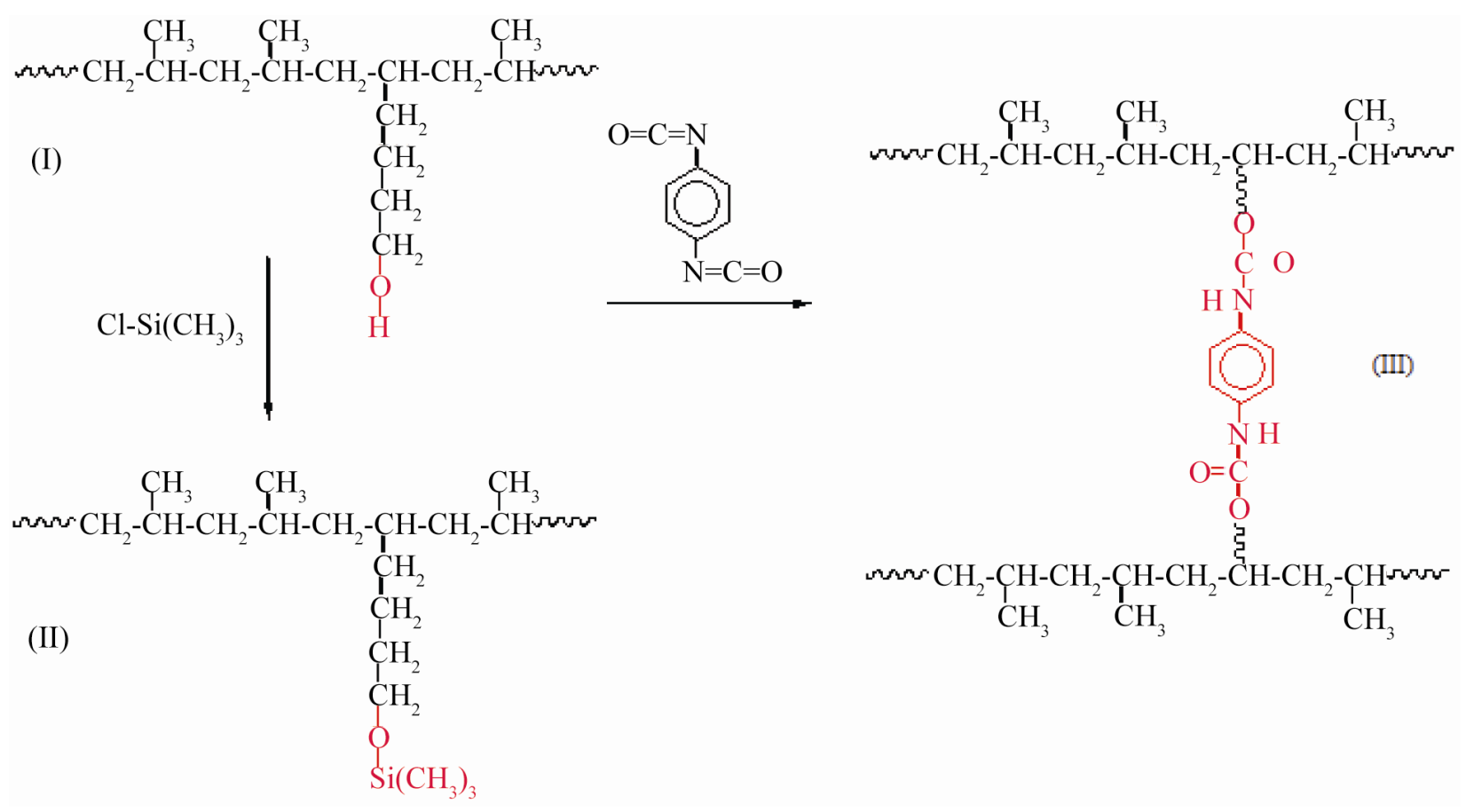



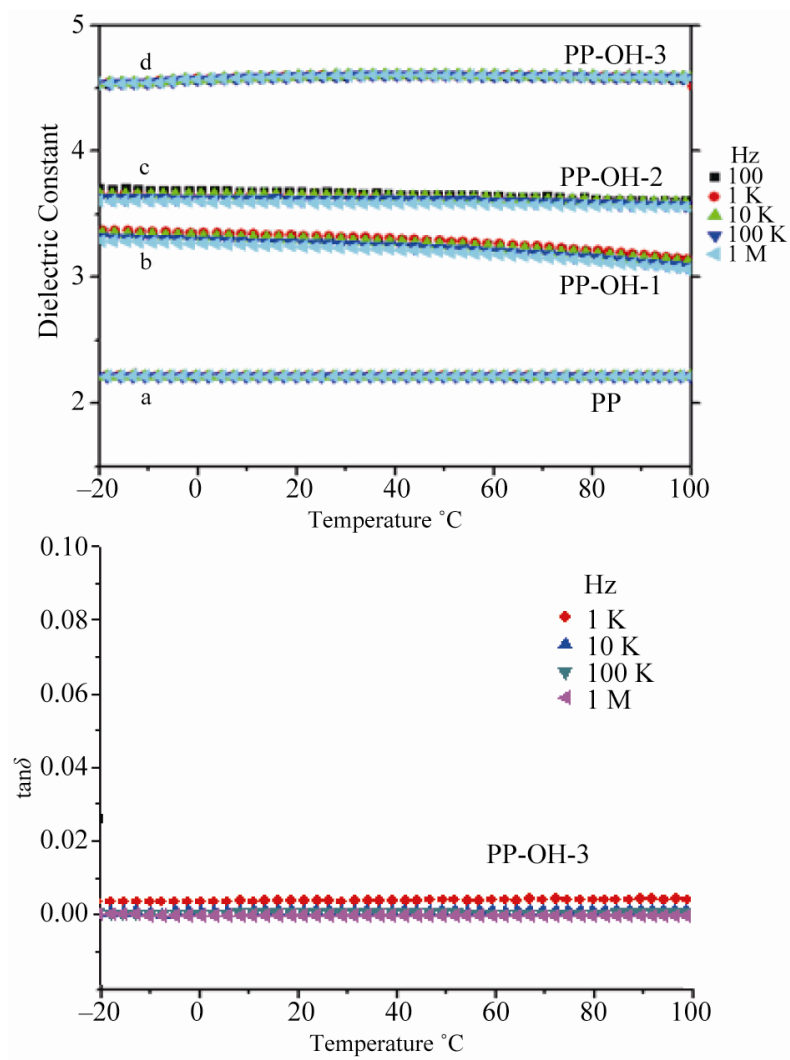

Figure 5. (top) Dielectric constants and (bottom) D-E loops for (a) PP and three PP-OH copolymers containing (b) 0.7, (c) 1.8 , and (d) $4.2 \mathrm{~mol} \% \mathrm{OH}$ content.

the unique contribution of $\mathrm{OH}$ polar groups in $\mathrm{PP}-\mathrm{OH}$ dielectric thin film; this not only increases polarizability but also provides a stable $\mathrm{PP}-\mathrm{OH}$ structure and morphology under a wide range of applied electric fields and elevated temperatures. This polar PP-OH polymer shall have a physical network structure (Figure 7) for performing fast polarization-depolarization cycles with low hysteresis and low energy loss.

As shown in Equation (3), the PP-OH (I) was also treated with phenyl diisocyanate to form chemically cross-linked x-PP (III) structure with urethane cross-linkers between polymer chains. In this urethane reaction, $\mathrm{PP}-\mathrm{OH}$ changes from a physical network (via H-bonding) to a chemical cross-linking network in x-PP. Figure 9 shows dielectric constant (top) and dielectric loss (bottom) of a x-PP copolymer (III) that was converted from the corresponding PP-OH (I) with $0.7 \mathrm{~mol} \% \mathrm{OH}$ content (PP-OH-1). Basically, we observe the same reversible polarization profile shown in PP-OH, with an increased dielectric constant that is independent on a wide range of frequencies and temperatures. Dielectric loss maintains extremely low up to $100^{\circ} \mathrm{C}$ and $1 \mathrm{M} \mathrm{Hz}$ frequency.

Figure 10(a) compares breakdown strength between three x-PP copolymers (III), containing 0.7, 1.4 and 2.1 mol $\%$ cross-linkers units, respectively, and the corre-
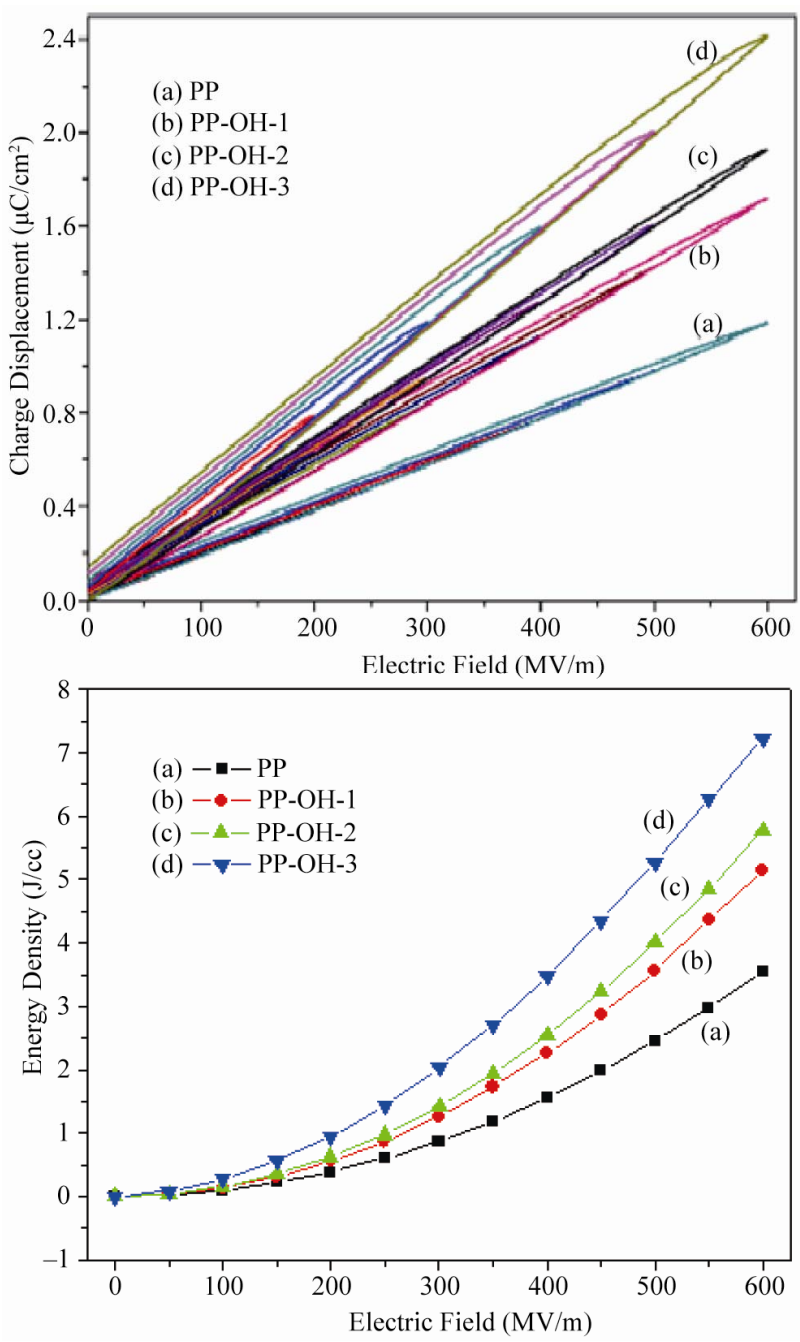

Figure 6. (top) D-E loops and (bottom) energy density for (a) PP and three PP-OH copolymers containing (b) 0.7, (c) 1.8, and (d) $4.2 \mathrm{~mol} \% \mathrm{OH}$ content under various electric fields.

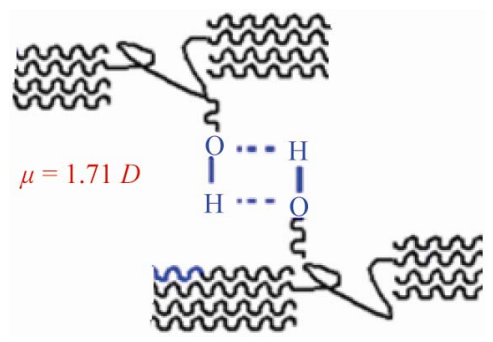

Figure 7. An illustration showing the network structure via H-bonding between $\mathrm{OH}$ groups.

sponding linear PP polymer. Figure 10(b) shows their Weibull distributions with the estimated $\alpha$ and $\beta$ values. All polymer films (thickness: $10-15 \mu \mathrm{m}$ ) were prepared by solution casting before thermal cross-linking. Evidently, the chemical cross-linking feature has a significant effect to the breakdown strength and breakdown distribution-higher cross-linking density higher break- 

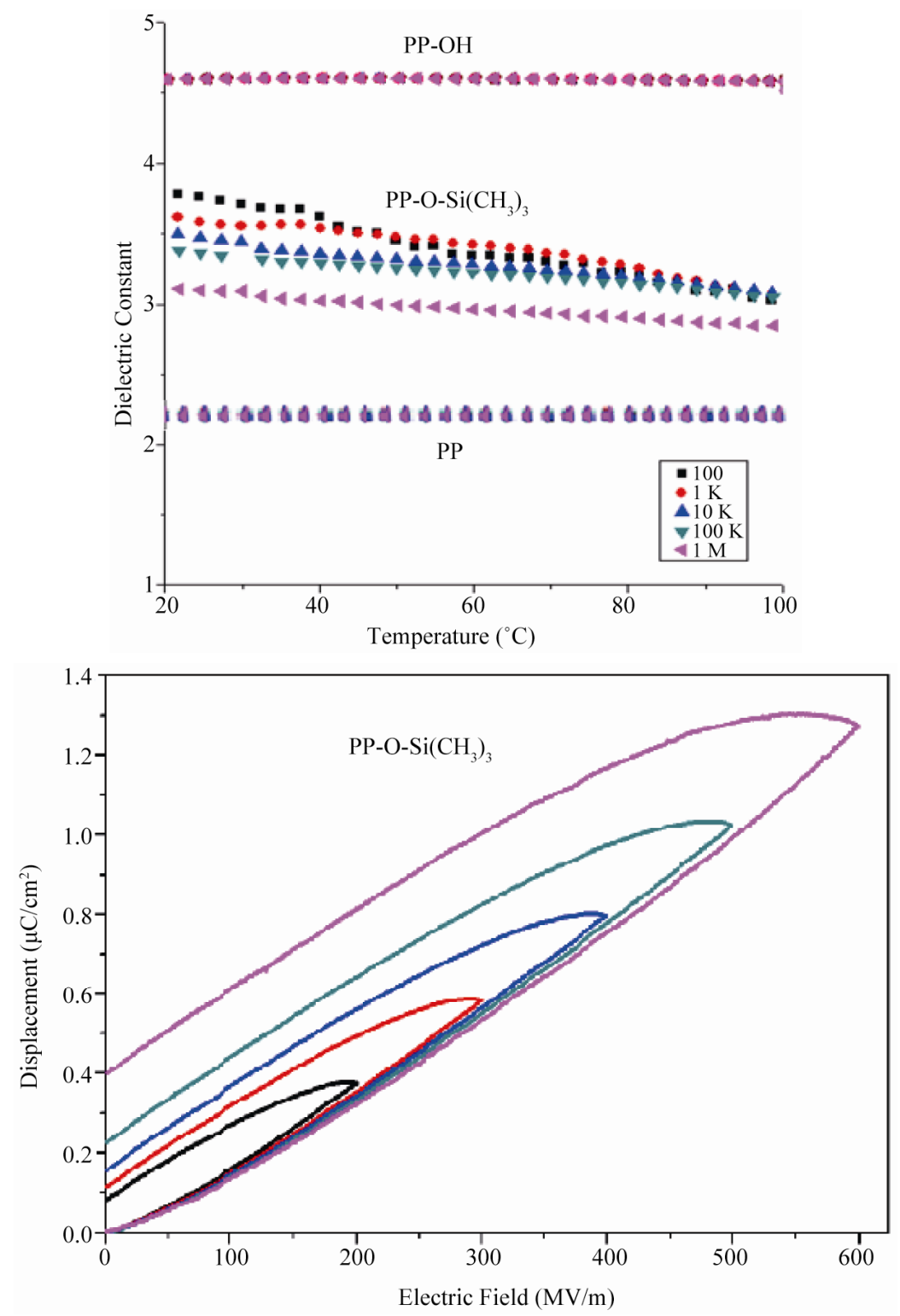

Figure 8. (top) Dielectric constant comparison between PP, PP-OH, and the corresponding PP-O-Si(CH $\mathrm{CH}_{3}$ with 4.2 mol\% comonomers, and (bottom) D-E loops of the PP-OSi $\left(\mathrm{CH}_{3}\right)_{3}$.

down strength ( $\alpha$ value) and narrower distribution $(\beta$ value). The x-PP-3 thin film shows a breakdown strength between 620 and $670 \mathrm{MV} / \mathrm{m}$ with a $\alpha$ value $=645 \mathrm{MV} / \mathrm{m}$, which is almost the same as those of the biaxially oriented PP (BOPP) films that are carefully conditioned (through stretching and annealing) to increase chain orientation and crystallinity and to reduce defects [23]. In addition, the x-PP-3 film exhibits a very narrow breakdown distribution with an exceptionally high $\beta$ value of 42 , indicating excellent dielectric reliability - a very important quality in capacitors [24]. The combination of high dielectric constant $(\varepsilon \sim 3)$, relatively high breakdown strength $(645 \mathrm{MV} / \mathrm{m})$, and low energy loss in $\mathrm{x}-\mathrm{PP}-3$ dielectric film offers a reliable energy density $>5 \mathrm{~J} / \mathrm{cc}$, significantly higher than the $2-3 \mathrm{~J} / \mathrm{cc}$ typically shown in BOPP capacitors.

\section{Conclusion}

In this paper, we systematically examine the structureproperty relationship of PP copolymers containing various comonomer units. Both PP-OH and x-PP copolymers having a network structure show reversible polarization with low loss and narrow breakdown distribution. Their dielectric constant maintains constant over a wide range of temperatures (between $-20^{\circ} \mathrm{C}$ and $100^{\circ} \mathrm{C}$ ), frequencies (between 100 and $1 \mathrm{M} \mathrm{Hz}$ ), and applied electric fields (> $600 \mathrm{MV} / \mathrm{m}$ ). The PP-OH (having $4.2 \mathrm{~mol} \% \mathrm{OH}$ content) based thin film capacitor displays a linear reversible 

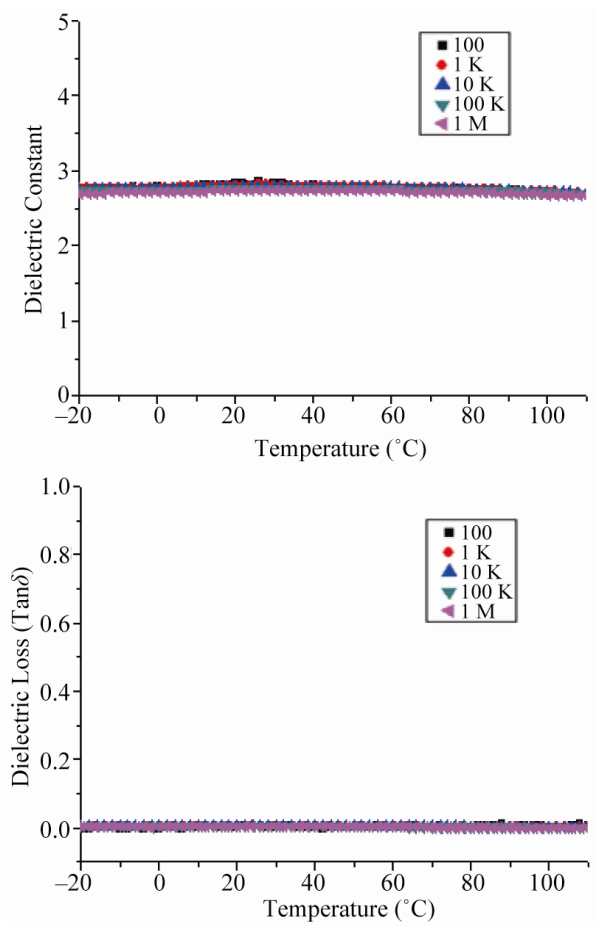

Figure 9. Dielectric constant (top) and dielectric loss (bottom) of an x-PP copolymer (III).
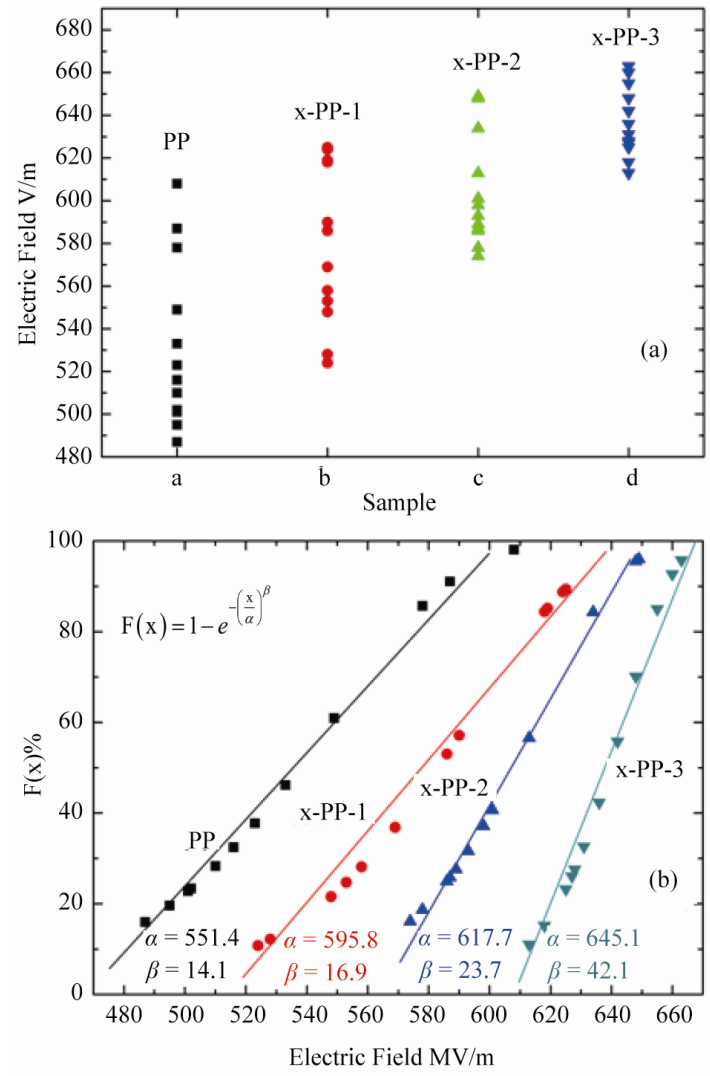

Figure 10. (a) Breakdown strength and (b) Weibull distribution for PP, $x-P P-1, x-P P-2$, and $x-P P-3$ dielectrics with $0.7,1.4$ and $2.1 \mathrm{~mol} \%$ cross-linkers, respectively. charge storage capacity with high releasing energy density $>7 \mathrm{~J} / \mathrm{cm}^{3}(2-3$ times of BOPP) after an applied electric field at $\mathrm{E}=600 \mathrm{MV} / \mathrm{m}$, without showing any significant increase in energy loss and remnant polarization at zero electric field.

\section{Acknowledgements}

This work was supported by the United States Office of Naval Research (Grant No. 00014-99-1-0443).

\section{REFERENCES}

[1] M. Winter and R. J. Brodd, "What Are Batteries, Fuel Cells, and Supercapacitors?" Chemical Reviews, Vol. 104, No. 10, 2004, pp. 4245-4270. doi:10.1021/cr020730k

[2] W. J. Sarjeant, “Advanced Power Sources for Space Missions, NAS-NRC (EEB) Committee on Advanced Spaced Based High Power Technologies," National Academy Press, Washington DC, 1989.

[3] W. J. Sarjeant, J. Zirnheld and F. W. MacDougall, "Capacitors," IEEE Transactions on Plasma Science, Vol. 26, No. 5, 1998, pp. 1368-1392. doi:10.1109/27.736020

[4] M. Villegas, J. F. Fernandez, C. Moure and P. Duran, "Preparation, Microstructural Development and Dielectric Properties of $\mathrm{Pb}\left(\mathrm{Mg}_{1 / 3} \mathrm{Nb}_{2 / 3}\right) \mathrm{O}_{3}-\mathrm{Pb}\left(\mathrm{Ti}_{\mathrm{x}} \mathrm{Zr}_{1-\mathrm{x}}\right) \mathrm{O}_{3}$ Multilayer Ceramic Capacitors," Journal of Materials Science, Vol. 29, No. 19, 1994, pp. 4999-5004. doi:10.1007/BF01151090

[5] G. R. Love, "Energy Storage in Ceramic Dielectrics," Journal of the American Ceramic Society, Vol. 73, No. 2, 1990, pp. 323-328.

[6] C. W. Reed and S. W. Cichanowski, "The Fundamentals of Aging in HV Polymer-Film Capacitors," IEEE Transactions on Dielectrics and Electrical Insulation, Vol. 1, No. 5, 1994, pp. 904-922. doi:10.1109/94.326658

[7] W. J. Sarjeant, F. W. MacDougall and D. W. Larson, "Energy Storage in Polymer Laminate Structures-Ageing and Diagnostic Approaches for Life Validation," IEEE Electrical Insulation Magazine, Vol. 13, No. 1, 1997, pp. 20-24. doi:10.1109/57.567394

[8] J. H. Tortai, N. Bonifaci, A. Denat and C. Trassy, "Diagnostic of the Self-Healing of Metallized Polypropylene Film by Modeling of the Broadening Emission Lines of Aluminum Emitted by Plasma Discharge," Journal of Applied Physics, Vol. 97, No. 5, 2005, Article ID: 53304. doi:10.1063/1.1858872

[9] M. Rabuffi and G. Picci, "Status Quo and Future Prospects for Metallized Polypropylene Energy Storage Capacitors," IEEE Transactions on Plasma Science, Vol. 30, No. 5, 2002, pp. 1939-1942.

[10] G. Picci and M. Rabuffi, "Pulse Handling Capability of Energy Storage Metallized Film Capacitors," IEEE Transactions on Plasma Science, Vol. 28, No. 5, 2000, pp. 1603-1606. doi:10.1109/27.901241

[11] J. A. Langston, J. Y. Dong and T. C. Chung, "One-Pot Process of Preparing Long Chain Branched Polypropylene (LCBPP) Using $\mathrm{C}_{2}$-Symmetric Metallocene Complex 
and A 'T' Reagent," Macromolecules, Vol. 38, No. 14, 2005, pp. 5849-5853. doi:10.1021/ma0506841

[12] J. A. Langston, R. H. Colby, T. Shimizu, T. Suzuki, M. Aoki and T. C. Chung, "Synthesis and Characterization of Long Chain Branched Isotactic Polypropylene (LCBPP) via Metallocene Catalyst and T-Reagent," Macromolecules, Vol. 40, No. 8, 2007, pp. 2712-2720. doi: $10.1021 / \mathrm{ma} 062111+$

[13] T. C. Chung and A. Petchsuk, "Ferroelectric Polymers with Giant Electrostriction; Based on Semicrystalline Terpolymers Containing Vinylidene Difluroride, Trifluroethylene and Third Monomer," US Patent No. 6,355,749, 2002.

[14] Z. C. Zhang and T. C. Chung, "Fluoro-Terpolymer Based Capacitors Having High Energy Density, Low Energy Loss, and High Pulsed Charge-Discharge Cycles," Macromolecules, Vol. 40, No. 4, 2007, pp. 783-785. doi:10.1021/ma0627119

[15] Z. C. Zhang and T. C. Chung, "The Structure-Property Relationship of PVDF-Based Polymers with Energy Storage and Loss under Applied Electric Fields," Macromolecules, Vol. 40, No. 26, 2007, pp. 9391-9397. doi:10.1021/ma071561e

[16] T. C. Chung and A. Petchsuk, "Synthesis and Properties of Ferroelectric Fluoro-Terpolymers with Curie Transition at Ambient Temperature," Macromolecules, Vol. 35, No. 20, 2002, pp. 7678-7684. doi:10.1021/ma020504c

[17] Z. Wang, Z. C. Zhang and T. C. Chung, "High Dielectric VDF/TrFE/CTFE Terpolymers Prepared by Hydrogenation of VDF/CTFE Copolymers; Synthesis and Charac- terization," Macromolecules, Vol. 39, No. 13, 2006, pp. 4268-4271. doi:10.1021/ma060738m

[18] T. C. Chung, "Functionalization of Polyolefins," Academic Press, London, 2002.

[19] T. C. Chung, "Synthesis of Functional Polyolefin Copolymers with Graft and Block Structures," Progress in Polymer Science, Vol. 27, No. 1, 2002, pp. 39-85. doi:10.1016/S0079-6700(01)00038-7

[20] X. Yuan, Y. Matsuyama and T. C. Chung, "Synthesis of Functionalized Isotactic Polypropylene Dielectrics for Electric Storage Application," Macromolecules, Vol. 43, No. 9, 2010, pp. 4011-4015. doi:10.1021/ma100209d

[21] W. Lin, Z. Shao, J. Y. Dong and T. C. Chung, "CrossLinked Polypropylene Prepared by PP Copolymers Containing Flexible Styrene Groups," Macromolecules, Vol. 42 , No. 11,2009 , pp. $3750-3754$. doi: $10.1021 / \mathrm{ma} 9002775$

[22] X. Yuan and T. C. Chung, "Cross-Linking Effect on Dielectric Properties of Polypropylene Thin Films and Applications in Electric Energy Storage," Applied Physics Letters, Vol. 98, No. 6, 2011, Article ID: 62901. doi: $10.1063 / 1.3552710$

[23] J. Artbauer, "Electric Strength of Polymers," Journal of Physics D: Applied Physics, Vol. 29, No. 2, 1996, p. 446. doi:10.1088/0022-3727/29/2/024

[24] C. C. Xu, J. Ho and S. A. Boggs, "Automatic Breakdown Voltage Measurement of Polymer Films," IEEE Electrical Insulation Magazine, Vol. 24, No. 6, 2008, pp. 30-34. doi:10.1109/MEI.2008.4665348 